\title{
DESIGN OF MOLECULAR ARCHITECTURES FOR POLYMERIC MESOPHASE FORMATION
}

\author{
Coleen Pugh,* Hui Liu, Stephen V. Arehart and Ramasubramanian Narayanan \\ Department of Chemistry, The University of Michigan, Ann Arbor, MI 48109-
} 1055, USA

\begin{abstract}
Based on the tendency of low molar mass liquid crystals composed of extended mesogens symmetrically disubstituted with long $n$-alkoxy substituents to exhibit smectic C mesophases, we have proposed that SCLCPs with laterally attached (vs. terminally attached) mesogens offer an ideal architecture for obtaining $\mathrm{S}^{*}$ mesophases. In particular, mesogens that typically form the desirable $\mathrm{s}_{\mathrm{C}}{ }^{*}-\mathrm{n}$ phase sequence can be laterally attached to the polymer backbone through a chiral spacer, which should result in high values of spontaneous polarization. Not only are we using mesogens which exhibit $\mathrm{sC}^{*}$-n phase sequences, we are also attempting to induce smectic layering into systems which typically form nematic mesophases by using immiscible hydrocarbon/fluorocarbon components and electron-donor-acceptor interactions. Thus far, the thermotropic behavior of poly\{5-I[[ $2^{\prime}, 5^{\prime}$-bis [ ( $\left.3^{\prime \prime}-f\right]$ uoro-4"dimethoxyphenyl)ethynyl]benzyl]oxy]carbonyl]bicyclo[2.2.1 ]hept-2-ene $] \mathrm{s}$ and poly [5-[I[2',5'-bis[(3"-fluoro-4"-methoxybenzoyl)oxy]benzyl] oxy]carbonyl]bicyclo[2.2.1 ]hept-2-ene ] $\mathrm{s}$ correspond to that of their low molar mass analogs. Preliminary results demonstrate that smectic layering is successfully induced in 2,5-bis[(4'-n-alkoxybenzoyl)oxy]toluenes and polynorbornenes with laterally attached 2,5-bis[(4'-n-alkoxybenzoyl)oxy]benzyl mesogens by terminating the $n$ alkoxy substituents with perfluorinated segments.
\end{abstract}

\section{INTRODUCTION}

Any potential applications of side-chain liquid crystalline polymers (SCLCPs) take advantage of their ability to freeze an anisotropic alignment below the glass transition, coupled with the fluidity of the mesophase. While SCLCPs generally can not compete with low molar mass liquid crystals (LMMLCs) for the same applications due to their higher viscosities, ferroelectric polymeric mesophases, such as chiral smectic $\mathrm{C}\left(\mathrm{sC}^{*}\right)$ mesophases, are very fluid and have fast switching times approaching those of LMMLCs. Materials which exhibit $\mathrm{sC}^{*}$ mesophases are also highly sought after because $\mathrm{s}^{*}$ mesophases spontaneously polarize if the helix is unwound (Ref. 1), such that a ferroelectric alignment can be frozen in below the glass transition. 
Although correlation of the structure of SCLCPs to their thermotropic behavior is limited, there is important information from the structure/property relationships of LMMLCs which can be used in designing polymers with $\mathrm{s}^{*}$ mesophases. The switching time $(\tau)$ from one anisotropic orientation to the opposite orientation is inversely proportional to the spontaneous polarization (P) according to eq. 1 ,

$$
\tau=\frac{\eta}{\text { PE }}
$$

in which $\eta$ is the viscosity and $E$ is the applied electric field (Ref. 2). Assuming that the fastest reorientational times are therefore obtained the higher the spontaneous polarization is, the following structure/property relationships should be considered. First, the highest absolute values of the spontaneous polarization are obtained the closer the chiral center is to the mesogenic core, the closer the chiral carbon is to the center of the molecule, and the stronger the dipole is at a given chiral carbon (Ref. 1). Second, materials having the $\mathrm{s}_{\mathrm{C}}^{*}-\mathrm{n}$ phase sequence possess much larger absolute values of spontaneous polarization compared to materials having the $\mathrm{S}_{\mathrm{C}}{ }^{*}$ - $\mathrm{S}_{\mathrm{A}}$ sequence (Ref. 1). In addition, a review of the literature on LMMLCs demonstrates that $\mathrm{S}_{\mathrm{C}}$ mesophases are common for extended mesogens which are symmetrically disubstituted with long $n$-alkoxy substituents. Some examples of LMMLCs which form $\mathrm{s}_{\mathrm{C}}$ mesophases include 2-chloro-N,N'-bis[4"- $n$-alkoxybenzylidene]phenylene-1,4diamines (Ref. 3), trans-1,4-bis[4'-n-alkoxyphenyl]cylclohexane dicarboxylates (Ref. 3), 3,6bis[4'-n-alkoxyphenyl]-1,2,4-triazines (Ref. 3), 2,6-bis[4'- $n$-alkoxyphenyl]-1,4,5,8tetrathiafulvalenes (Ref. 3), 2,5-bis[4'-n-alkoxyphenyl]thiazolo[5,4-d]thiazoles (Ref. 3) and 1,4-bis[(3'-fluoro-4'-n-alkoxyphenyl)ethynyl]benzenes (Ref. 4).

Since $\mathrm{s}_{\mathrm{C}}$ mesophases are common for symmetrically disubstituted extended mesogens with long $n$-alkoxy substituents, a more rational design for polymers which might exhibit $\mathrm{s}_{\mathrm{C}}$ mesophases would be to incorporate this type of mesogen. One way to incorporate symmetrically disubstituted extended mesogens is to attach them laterally to the polymer backbone, with a chiral group in either the spacer or laterally attached at the center of the mesogen. However, it is commonly believed that SCLCPs with laterally attached mesogens are capable of forming only nematic mesophases. Although almost all laterally attached SCLCPs prepared to date exhibit only nematic mesophases (Refs. 5,6), their mesogens correspond to LMMLCs which show little tendency to organize into layers (Ref. 3).

We are taking three approaches to induce smectic layering in SCLCPs with laterally attached mesogens. First, we are using mesogens which do exhibit the desired $s^{-}-n-i$ phase sequence, starting with 1,4-bis[(3'-fluoro-4'- $n$-alkoxyphenyl)ethynyl]benzenes (Ref. 4$)$. In order to demonstrate that smectic mesophases should not be uncommon for SCLCPs with laterally attached mesogens, we are also attempting to force the mesogens into a smectic alignment by terminating the $n$-alkoxy substituents with perfluorinated segments. This is based on the observation that diblock $\mathrm{H}\left(\mathrm{CH}_{2}\right)_{n}\left(\mathrm{CF}_{2}\right)_{\mathrm{m}} \mathrm{F}$ and triblock $\mathrm{F}\left(\mathrm{CF}_{2}\right)_{\mathrm{m}}\left(\mathrm{CH}_{2}\right)_{n}\left(\mathrm{CF}_{2}\right)_{\mathrm{m}} \mathrm{F}$ molecules with $4 \leq n \leq 14$ and $m \geq 6$ undergo solid-solid transitions into a smectic mesophase before melting into an isotropic state due to the immiscibility of the hydrocarbon and 


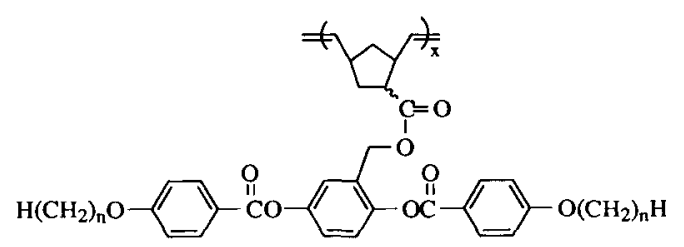

Tab. 1. Molecular weight and phase transitions of polynorbornenes with laterally attached 2,5-bis[(4'-n-alkoxybenzoyl)oxy]benzyl mesogens (Ref. 6).

\begin{tabular}{|c|c|c|c|c|}
\hline $\mathrm{n}$ & $\mathrm{X}_{\mathbf{n}}$ & $\mathrm{M}_{\mathbf{n}} \times 10^{-3}$ & $\mathrm{PDI}$ & Phase Transitions $\left({ }^{\circ} \mathrm{C}\right)$ \\
\hline 1 & 5.1 & 2.7 & 1.16 & $\mathrm{~g} 79 \mathrm{n} 131 \mathrm{i}$ \\
1 & 8.2 & 4.3 & 1.20 & $\mathrm{~g} 90 \mathrm{n} 146 \mathrm{i}$ \\
1 & 14 & 7.2 & 1.12 & $\mathrm{~g} 91 \mathrm{n} 155 \mathrm{i}$ \\
1 & 39 & 21 & 1.13 & $\mathrm{~g} 97 \mathrm{n} 163 \mathrm{i}$ \\
1 & 45 & 24 & 1.13 & $\mathrm{~g} 98 \mathrm{n} 164 \mathrm{i}$ \\
1 & 100 & 53 & 1.16 & $\mathrm{~g} 97 \mathrm{n} 163 \mathrm{i}$ \\
2 & 32 & 18 & 1.19 & $\mathrm{~g} 92 \mathrm{n} 172 \mathrm{i}$ \\
3 & 44 & 26 & 1.24 & $\mathrm{~g} 83 \mathrm{n} 140 \mathrm{i}$ \\
4 & 23 & 14 & 1.17 & $\mathrm{~g} 73 \mathrm{n} 138 \mathrm{i}$ \\
5 & 45 & 29 & 1.18 & $\mathrm{~g} 60 \mathrm{n} 123 \mathrm{i}$ \\
6 & 66 & 44 & 1.24 & $\mathrm{~g} 56 \mathrm{n} 126 \mathrm{i}$ \\
\hline
\end{tabular}

fluorocarbon segments (Ref. 7). Since there is greater interaction between the mesogens in a smectic vs. nematic alignment, the third approach toward inducing smectic layering will be to copolymerize one monomer containing an electron-rich mesogen with a second monomer containing an electron-poor mesogen.

In order to test the ability of these three approaches to induce smectic layering in SCLCPs with laterally attached mesogens, we prefer to maintain the basic structure of the polynorbornenes containing 1,4-bis[(4'-n-alkoxybenzoyl)oxy]benzene mesogens shown in Tab. 1. The polynorbornenes shown in Tab, 1 were prepared by ring-opening metathesis polymerization and are the most well-defined SCLCPs with laterally attached mesogens that have been prepared to date (Ref. 6). Both the molecular weight dependence of the phase transitions and the effect of the length of the $n$-alkoxy substituents are known. That is, both the glass and the nematic-isotropic transition temperatures become independent of molecular weight at approximately 25 repeat units. The glass transition and isotropization temperatures decrease with increasing length of the $n$-alkoxy substituent. Isotropization decreases in an odd-even alternation, with the even-membered substituents having broader and more stable mesophases than the odd-membered substituents.

\section{SMECTIC MESOPHASES INDUCED BY INCORPORATING LOW MOLAR MASS ANALOGS WHICH EXHIBIT $s_{C}$ MESOPHASES}

In order to determine how well low molar mass liquid crystals serve as model compounds for these SCLCPs, the complete series of 1,4-bis[( $3^{\prime}$-fluoro-4'-nalkoxyphenyl)ethynyl]benzenes with $n=1-12$ was synthesized and characterized. Those with $n=1-6$ were prepared by a one pot, solid-liquid phase transfer, $\mathrm{Pd}(0) / \mathrm{Cu}(\mathrm{I})$ catalyzed, three step 


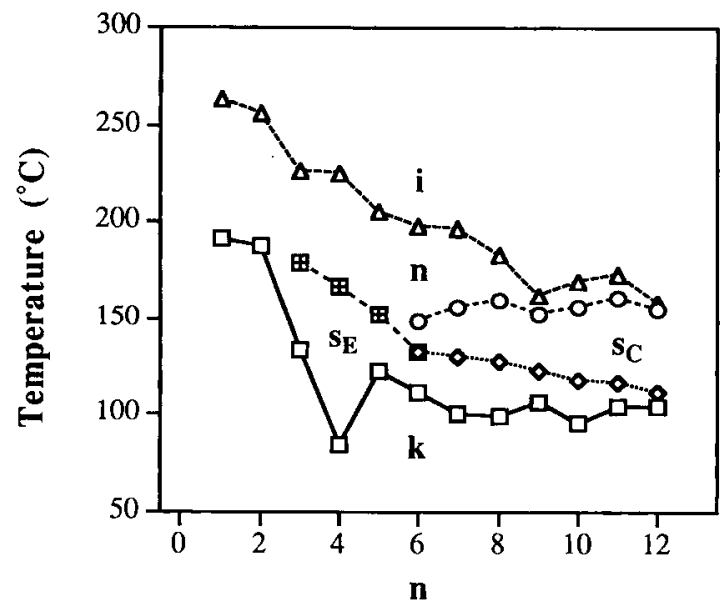

Fig. 1. Phase transition temperatures of 1,4 -bis[(3'-fluoro-4'- $n$-alkoxyphenyl)ethynyl]benzenes as a function of the length of the $n$-alkoxy substituents.

coupling of 1,4-diiodobenzene with two equivalents of the appropriate 1-bromo-3-fluoro-(4- $n$ alkoxy)benzene through an acetylene bridge as described previously for the synthesis of the $n=7-12$ derivatives (Ref. 4). Fig. 1 and Tab. 2 present the thermotropic behavior of the entire series. The $\mathrm{s}^{-} \mathrm{n}-\mathrm{i}$ phase sequence is exhibited when $n=6-12$. We expect the corresponding SCLCPs to display similar behavior.

We initially planned to prepare the monomers by first synthesizing the mesogen

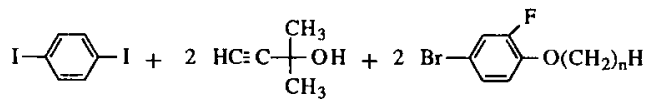<smiles>COc1ccc(C#Cc2ccc(C#Cc3ccc(OCCO)c(F)c3)cc2)cc1C(=O)OCCO</smiles>

Tab. 2. Thermotropic behavior of 1,4-bis[3'-fluoro-4'- $n$-alkoxyphenyl)ethynyl]benzenes.

\begin{tabular}{|c|c|c|c|c|c|c|}
\hline $\mathrm{n}$ & \multicolumn{5}{|c|}{ Phase Transitions $\left({ }^{\circ} \mathrm{C}\right)$} & Ref. \\
\hline $\begin{array}{l}1 \\
2 \\
3 \\
4 \\
5 \\
6 \\
\end{array}$ & $\begin{array}{ll}\mathrm{k} & 192 \\
\mathrm{k} & 188 \\
\mathrm{k} & 134 \\
\mathrm{k} & 84 \\
\mathrm{k} & 122 \\
\mathrm{k} & 112 \\
\end{array}$ & & $\begin{array}{l}S_{E} 179 \\
S_{E} 167 \\
S_{E} 152 \\
S_{E} 132\end{array}$ & sc 148 & $\begin{array}{l}\text { n } 263 i \\
\text { n } 256 i \\
\text { n } 226 i \\
\text { n } 225 i \\
\text { n } 205 i \\
\text { n } 198 i\end{array}$ & $\begin{array}{l}\text { current } \\
\text { current } \\
\text { current } \\
\text { current } \\
\text { current } \\
\text { current }\end{array}$ \\
\hline $\begin{array}{c}7 \\
8 \\
9 \\
10 \\
11 \\
12\end{array}$ & $\begin{array}{rr}\mathbf{k} & 57 \\
\mathbf{k} & 99 \\
\mathbf{k} & 107 \\
\mathbf{k} & 95 \\
\mathbf{k} & 82 \\
\mathbf{k} & 70\end{array}$ & $\begin{array}{ll}k & 100 \\
k & 95 \\
k & 104 \\
k & 104\end{array}$ & $\begin{array}{l}S_{E} \quad 130 \\
S_{E} 128 \\
S_{E} 123 \\
S_{E} 117 \\
S_{E} 116 \\
S_{E} 112\end{array}$ & $\begin{array}{ll}\mathrm{s}_{C} & 156 \\
\mathrm{~s}_{C} & 159 \\
\mathrm{~s}_{C} & 152 \\
\mathrm{~s}_{C} & 156 \\
\mathrm{~s}_{C} & 161 \\
\mathrm{~s}_{C} & \mathbf{1 5 4}\end{array}$ & $\begin{array}{l}\text { n } 196 i \\
\text { n } 183 i \\
\text { n } 162 i \\
\text { n } 169 \mathrm{i} \\
\text { n } 173 \mathrm{i} \\
\text { n } 158 \mathrm{i}\end{array}$ & $\begin{array}{l}4 \\
4 \\
4 \\
4 \\
4 \\
4\end{array}$ \\
\hline
\end{tabular}


functionalized with a benzylic alcohol, and then esterifying that with bicyclo[2.2.1]hept-2-ene-5-carboxyl chloride. Methyl 2,5-diiodobenzoate was reacted with two equivalents of 2 methyl-3-butyn-2-ol and 4-bromo-2fluoroanisole by the same one pot method described above, except that KO'Bu and 18-crown-6 were used as the base and phase transfer catalyst, respectively, in order to avoid hydrolysis of the ester. However, following the reaction by ${ }^{1} \mathrm{H}-\mathrm{NMR}$ demonstrated that once the aryl halide reacted at the 5-position, the methyl resonance of the ester was consumed.

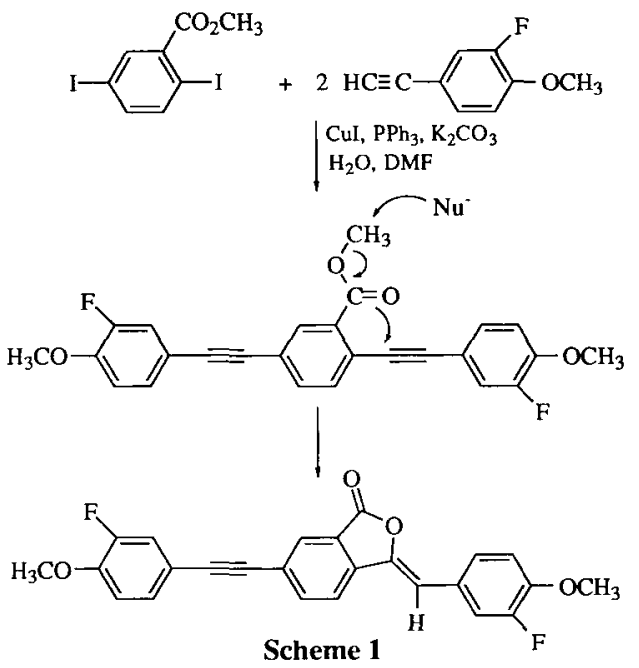

Although there are numerous reports of $\mathrm{Pd}(0) / \mathrm{Cu}(\mathrm{I})$ catalyzed couplings of acetylenes with aryl halides containing ester groups (Ref. 8), none involve an ester ortho to the halide. However, pentaiodobenzoic acid was reported to couple with phenylacetylene to yield penta(phenylethynyl)benzoic acid in $32 \%$ yield (Ref. 9), although the ${ }^{1} \mathrm{H}$-NMR resonance of $-\mathrm{COOH}$ appears remarkably upfield at $2.72 \mathrm{ppm}$. This coupling is in contrast to the facile synthesis of 3-benzylidenephthalides under Stephens-Castro conditions by coupling acetylenes with aryl halides substituted at the ortho position with nucleophilic - COOH (Ref. 10). In addition, the coupled product should not be stable in this form. For example, 2tolancarboxylic acid isomerizes to 3-(4-carboxybenzylidene)phthalide on prolonged heating in ethanol as a recrystallization solvent (Ref. 11). We found that reaction of 2-iodo-benzoic acid and trimethylsilyl acetylene under Heck's conditions (Ref. 9) yields primarily 3trimethylsilylvinylphthalide.

$\mathrm{Cu}(\mathrm{I}) / \mathrm{PPh}_{3}$ catalyzed coupling of both 2-iodobenzoic acid and methyl 2-iodobenzoate with phenylacetylene yielded 3-phenylisocoumarin rather than the phthalide (Ref. 12), whereas the addition of one equivalent of water was reported to prevent nucleophilic attack of the carboxylic acid and ester groups at the triple bond. In our hands, $\mathrm{Cu}(\mathrm{I}) / \mathrm{PPh}_{3}$ catalyzed coupling of methyl 2,5-diiodobenzoate with 1-(3'-fluoro-4'-methoxyphenyl)acetylene in DMF using $\mathrm{K}_{2} \mathrm{CO}_{3}$ as base yielded a phthalide even in the presence of one equivalent $\mathrm{H}_{2} \mathrm{O}$ (Scheme 1). Nevertheless, since cyclization is a nucleophilic reaction, any attempt at reducing the desired 2,5-bis[(3'-fluoro-4'-methoxyphenyl)ethynyl]benzoic acid or methyl 2,5-bis[(3'fluoro-4'-methoxyphenyl)ethynyl]benzoate would surely result in a phthalide, isocoumarin, benzofuran or benzopyran derivative. Therefore, the ester group of methyl 2,5-diiodobenzoate should be reduced to a benzyl alcohol, and esterified before coupling with the appropriate arylacetylenes. 2-Iodobenzylacetate was prepared as a model for 5-\{[(2',5'-diiodobenzyl)oxy $\}$ - 


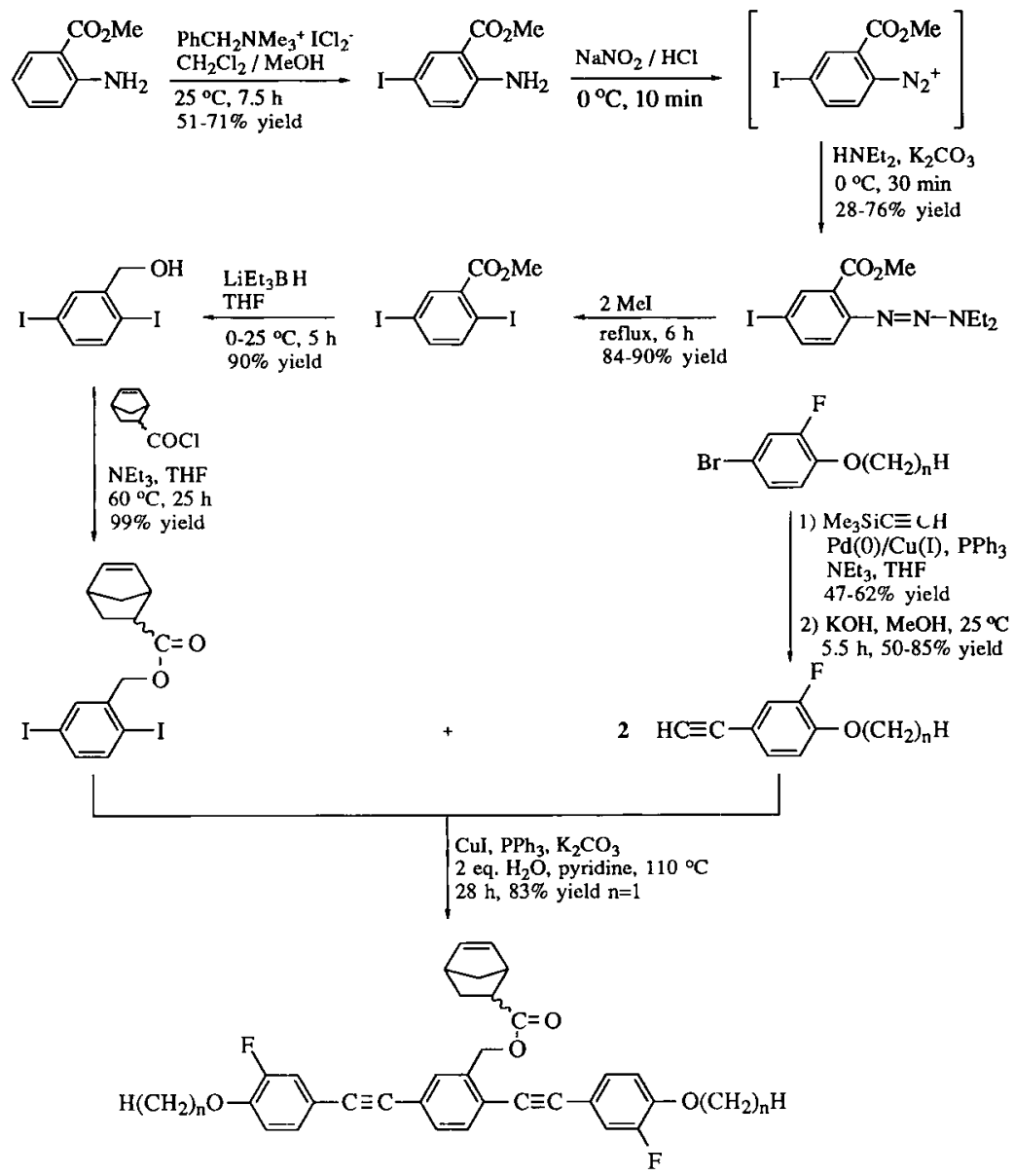

\section{Scheme 2}

carbonyl \}bicyclo[2.2.1]hept-2-ene. It couples with 4-bromo-2-fluoroanisole without isomerization to yield the diarylacetylene shown in eq. 2 in $42 \%$ yield.

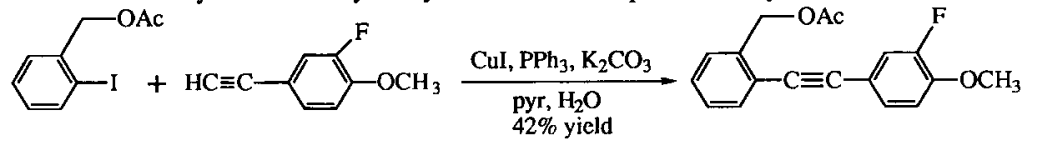

The monomer(s) were synthesized by the route shown in Scheme 2. Methyl anthranilate was iodinated para to the amine group using benzyltrimethylammonium dichloroiodate (Ref. 13). The amine group was replaced with iodine following a literature procedure (Ref. 14) in which a triazine intermediate formed via the diazonium salt was treated in a closed system with methyl iodide. The ester group was then selectively reduced using 
lithium triethylborohydride (Ref. 15), and the resulting benzyl alcohol was esterified with bicyclo[2.2.1]hept-2-ene-5carboxyl chloride in the presence of triethylamine. This functionalized aryl diiodide was then coupled with two equivalents of a preformed 1-(3'-fluoro-4'-nalkoxyphenyl)acetylene in the presence of $\mathrm{CuI}$ to generate the monomer(s).

Preliminary results demonstrate that these mesogenic norbornene monomers can be polymerized in a controlled manner by ring-opening
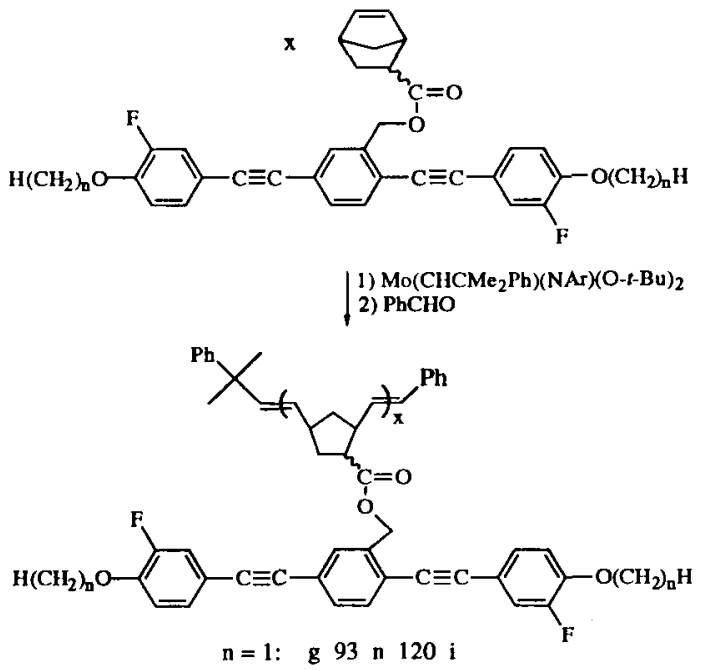

Scheme 3 metathesis polymerization using $\mathrm{Mo}\left(\mathrm{CHCMe}_{2} \mathrm{Ph}\right)\left(\mathrm{N}-2,6-\mathrm{C}_{6} \mathrm{H}_{3}-i-\mathrm{Pr}_{2}\right)(\mathrm{O}-t-\mathrm{Bu})_{2}$ as the initiator

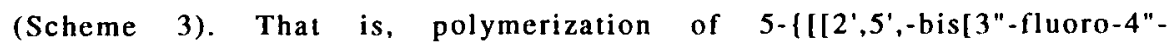
methoxyphenyl)ethynyl]benzyl]oxy]carbonyl \}bicyclo[2.2.1] molecular weight of $2.3 \times 10^{4}$ resulted in a polymer with $M_{n}=2.9 \times 10^{4}$ and $M_{w} / M_{n}=1.12$ as determined by gel permeation chromatography relative to polystyrene standards. In addition to a glass transition at $93^{\circ} \mathrm{C}$, this polynorbornene forms only a nematic mesophase, which corresponds to the thermotropic behavior of its low molar mass analog, 1,4-bis[(3'-fluoro-4'methoxyphenyl)ethynyl]benzene.

\section{SMECTIC MESOPHASES INDUCED BY IMMISCIBLE COMPONENTS}

Our second approach for inducing smectic layering in nematic compounds and in SCLCPs with laterally attached mesogens is to terminate the mesogen's $n$-alkoxy substituents with immiscible fluorocarbon segments. As outlined in Scheme 4, the 2,5-bis $\left\{\left[4^{\prime}-n\right.\right.$ (perfluoroalkyl)alkoxybenzoyl]oxy foluene model compounds were prepared by etherification of ethyl 4-hydroxybenzoate with an $n$-bromoolefin, followed by saponification of the resulting ethyl (4-n-alkenyloxy)benzoates, and coupling of the benzoic acids with methylhydroquinone prior to introduction of the perfluorinated segment. Perfluorinated segments were introduced by free radical addition of perfluorohexyl or perfluorooctyl iodide across the double bonds, followed by reduction of the iodide using tributyltin hydride under free radical conditions. These model compounds are being functionalized at the benzylic position with a norbornylpolymerizable group following free radical bromination. The resulting monomers will be polymerized by ring-opening metathesis polymerization.

The thermotrodic behavior of the re. Iting 2.5-bis\{[4'-n-(berfluoroalkvl)alkoxy- 


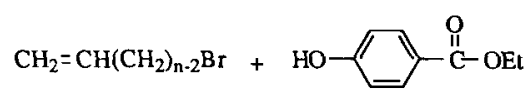

1) $\mathrm{K}_{2} \mathrm{CO}_{3}$, aq. EtOH

reflux, 30-78\% yield

2) $\mathrm{NaOH}, \mathrm{EtOH}$, reflux

3) $\mathrm{HCl}, \quad 64-94 \%$ yield

$\mathrm{CH}_{2}=\mathrm{CH}\left(\mathrm{CH}_{2}\right)_{\mathrm{n}-2} \mathrm{O} \longrightarrow \stackrel{\mathrm{O}}{\mathrm{C}-\mathrm{OH}}$

\begin{tabular}{l|l}
$25{ }^{\circ} \mathrm{C}, \mathrm{CH}_{2} \mathrm{Cl}_{2}$ \\
DCC, DMAP, $p$-TsOH \\
$64-91 \%$ yield
\end{tabular}

$\left.\mathrm{CH}_{2}=\mathrm{CH}\left(\mathrm{CH}_{2}\right)_{\mathrm{n}-2} \mathrm{O}-\mathrm{CO}-\mathrm{CCH}_{2}\right)_{\mathrm{n}-2} \mathrm{CH}=\mathrm{CH}_{2}$

$\mathrm{F}\left(\mathrm{CF}_{2}\right)_{\mathrm{m}} \mathrm{I}$, AIBN

reflux, toluene

$27-64 \%$ yield

$\mathrm{F}\left(\mathrm{CF}_{2}\right)_{\mathrm{m}} \mathrm{CH}_{2} \stackrel{\mathrm{HC}}{\mathrm{C}}\left(\mathrm{CH}_{2}\right)_{\mathrm{n}-2} \mathrm{O} \longrightarrow \mathrm{C}$

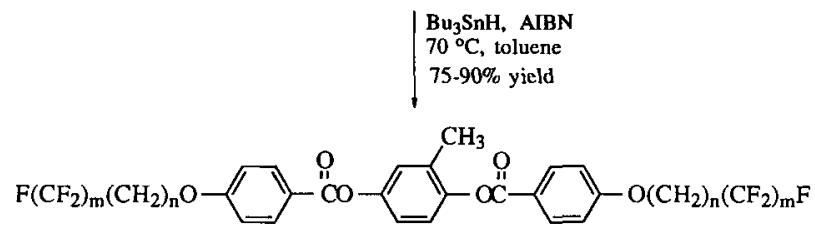

Scheme 4

benzoyl]oxy foluenes are summarized in Tab. 3 . Comparison of the data in Tables 3 and 4 demonstrates that termination of the $n$-alkoxy substituents with perfluorinated segments induces smectic layering in these low molar mass liquid crystals. That is, whereas the $2,5-$ bis[(4'-n-alkoxybenzoyl)oxy]toluenes form nematic mesophases, the 2,5-bis $\left\{\left[4^{\prime}-n\right.\right.$ (perfluoroalkyl)alkoxybenzoyl]oxy\}toluenes exhibit what appears to be a $\mathrm{sc}^{-\mathrm{s}_{\mathrm{A}}}$ phase sequence. Although the temperature range of the $s_{A}$ mesophases are relatively narrow (4-10 ${ }^{\circ} \mathrm{C}$ ), that of the $\mathrm{sC}_{\mathrm{C}}$ mesophases are quite broad $\left(77-99^{\circ} \mathrm{C}\right)$. Termination of the $n$-alkoxy substituents with perfluorohexyl and perfluorooctyl groups has little effect on either the melting or isotropization temperatures compared to the 2,5-bis[(4'-nalkoxybenzoyl)oxy]toluenes without perfluorinated segments. Smectic $\mathrm{C}$ and/or $\mathrm{s}_{\mathrm{A}}$ mesophases were also formed by other LMMLCs containing a perfluoroalkyl substituent (Ref. 16). Preliminary results demonstrate that the polynorbornenes also form smectic mesophases. 


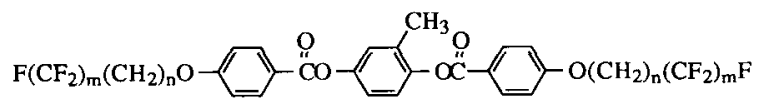

Tab. 3. Thermotropic behavior of 2,5-bis $\left\{\left[44^{\prime}-n-\right.\right.$ (perfluoroalkyl)alkyloxybenzoyl]oxy\}toluenes.

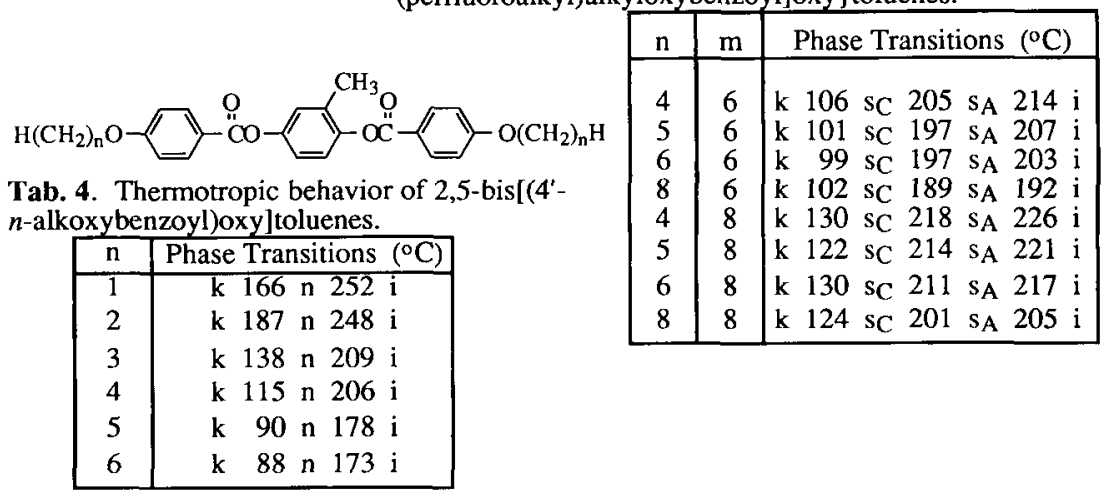

\section{SMECTIC MESOPHASES INDUCED BY ELECTRON-DONOR-ACCEPTOR INTERACTIONS}

In order to test the ability of EDA interactions to induce smectic layering in SCLCPs with laterally attached mesogens, we prefer to maintain the basic structure of the polynorbornenes containing 1,4-bis[(4'-n-alkoxybenzoyl)oxy]benzene mesogens shown in Tab. 1. We have chosen the three nitrogen-containing mesogens based on heterocyclic aromatic rings or aniline Electron Donors? derivatives shown in Scheme 5 as possible electron-donors. Since "electron-donor" and "electron-acceptor" are relative terms, the heterocyclic aromatic compounds may act as acceptors with compounds having low ionization potentials, or as donors with compounds having high electron affinities (Ref. 17). Fluorinated derivatives of the 1,4-bis[(4'- $n$-alkoxybenzoyl)oxy]toluenes are being tested as potential electron-acceptors.

We have set two requirements which must be satisfied by each component in<smiles>CCOc1ccc(C(=O)Oc2ccc(OC(=O)c3ccc(OC[14CH2])cc3)nn2)cc1</smiles><smiles>CCCCOc1ccc(C(=O)Oc2ccc(OC(=O)c3ccc(OCCCC)nc3)c(C)c2)cn1</smiles><smiles>[R]CN([Y])c1ccc(C(=O)Oc2ccc(C(=O)c3ccc(N([Y])C)cc3)cc2C)cc1</smiles>

Electron Acceptors?

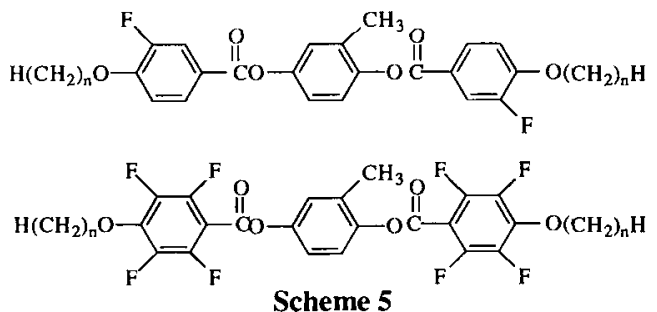




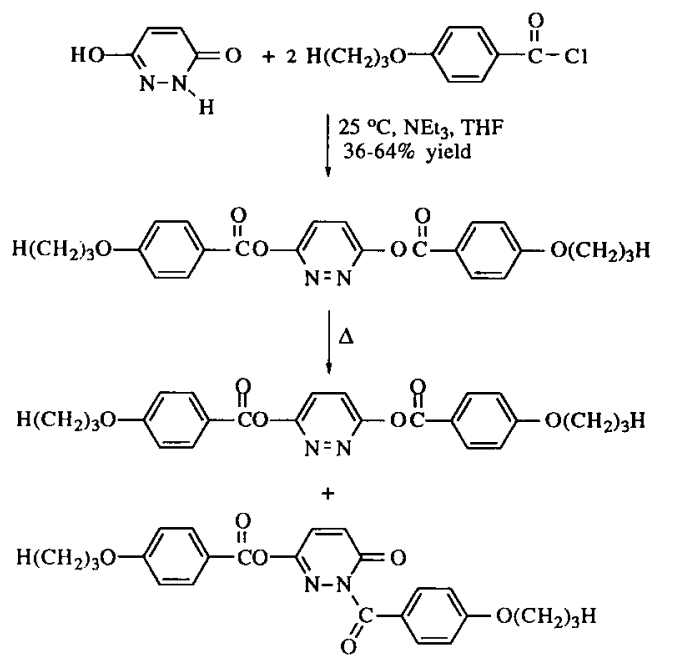

Tab. 5. Clearing and decomposition temperatures of 3,6-bis[(4'-nalkoxybenzoyl)oxy]pyridazines.

\begin{tabular}{|c|c|c|c|c|}
\hline $\mathbf{n}$ & $\begin{array}{c}\text { Yield } \\
(\%)\end{array}$ & $\begin{array}{c}\text { Clearing Temperature } \\
\left({ }^{\circ} \mathrm{C}\right)\end{array}$ & $\begin{array}{c}\text { Decomposition Temp. } \\
\left({ }^{\circ} \mathrm{C}\right)\end{array}$ & $\begin{array}{c}\text { \% Wt. } \\
\text { Loss }\end{array}$ \\
\hline 1 & 48 & 167 & 269 & 74 \\
3 & 54 & 168 & 325 & 86 \\
4 & 44 & 175 & 350 & 76 \\
5 & 46 & 168 & 341 & 82 \\
6 & 64 & 164 & 344 & 83 \\
7 & 60 & 154 & 350 & 83 \\
8 & 64 & 156 & 348 & 93 \\
9 & 36 & 146 & 350 & 91 \\
10 & 45 & & & 77 \\
\hline
\end{tabular}

order for it to be used for determining the ability of EDA interactions to induce smectic mesophase formation in SCLCPs with laterally attached mesogens and in the corresponding low molar mass model compounds. First, the homopolymers and their individual model compounds must exhibit only nematic mesophases. Therefore, the series of model compounds shown in Scheme 5 and their corresponding homopolymers will be prepared in order to better understand the structural requirements for maintaining the nematic mesophase of SCLCPs with laterally attached mesogens based on 1,4-bis[(4'-n-alkoxybenzoyl)oxy]benzyl derivatives. Second, their mixtures should show some evidence of forming an EDA interaction.

The 3,6-bis[(4'-n-alkoxybenzoyl)oxy]pyridazines are most logically synthesized by diesterification of 3,6-dihydroxypyridazine, which exists in its tautomeric form and is thus known as maleic hydrazide. Therefore, diesterification could potentially be complicated by competing nucleophilic attack by nitrogen (Ref. 18). Although only monoesterifications of maleic hydrazide using stoichiometric acid chloride or anhydride had bcen reported previously (Ref. 19), we were able to prepare the 3,6-bis[(4'-n-alkoxybenzoyl)oxy]pyridazines in 36 to $64 \%$ yield using two equivalents of the corresponding 4- $n$-alkoxybenzoyl chlorides. However, the resulting diesters are thermally unstable and rearrange in both the melt and in solution: 


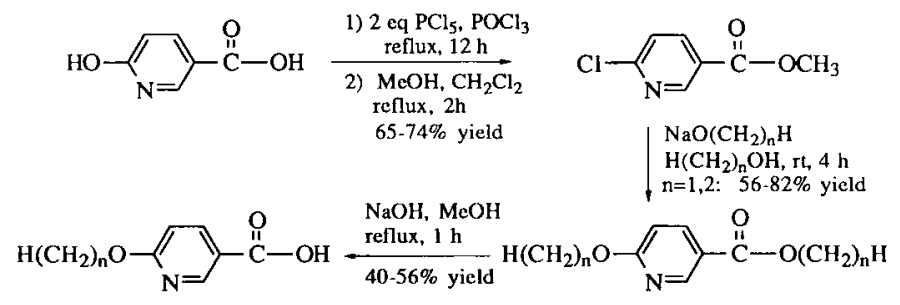

$$
\text { 1) } \mathrm{PCl}_{5}, \mathrm{POCl}_{3}
$$<smiles>CCCCOc1ccc(C(=O)Oc2ccc(OC(=O)c3ccc(OC)nc3)cc2C)cn1</smiles>

Scheme 6

rearrangement following diesterification or during the recrystallization may account for the low yields. Since the 3,6-bis[(4'-n-alkoxybenzoyl)oxy]pyridazines are thermally unstable, such that heating results in a mixture of starting compound and rearranged product(s), their thermotropic behavior can not be determined and only their initial clearing and decomposition temperatures are reported in Tab. 5 . However, this thermal instability will not prevent their use as one member of an EDA pair if complexation prevents rearrangement.

The syntheses of the pyridine based model compounds are shown in Scheme 6.6 Hydroxynicotinic acid was chosen instead of 5-hydroxynicotinic acid due to its inability to decarboxylate. It was converted to methyl 6chloronicotinate by chlorination of both the alcohol and carboxylic acid groups using phosphorus pentachloride in phosphorus oxychoride, followed by esterification with methanol. The 6$n$-alkoxynicotinic acids are being prepared by nucleophilic substitution of the chloride with the

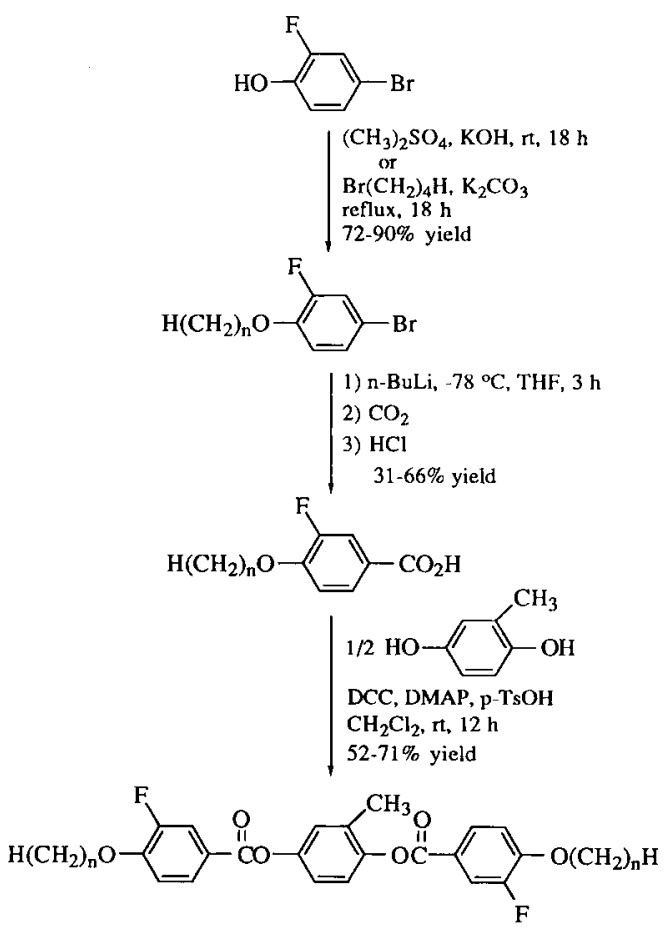

Scheme 7

Scheme 7 
<smiles>O=C(O)c1c(F)c(F)c(F)c(F)c1F</smiles>

$\mathrm{KOH}, \mathrm{H}\left(\mathrm{CH}_{2}\right)_{\mathrm{n}} \mathrm{OH}$

$25^{\circ} \mathrm{C}, 18 \mathrm{~h}$

$\mathrm{n}=1: 56-68 \%$ yield<smiles>COc1c(F)c(F)c(C(=O)O)c(F)c1OCCO</smiles>

DCC, DMAP, $p$-TsOH

$\mathrm{CH}_{2} \mathrm{Cl}_{2}, 25^{\circ} \mathrm{C}, 12 \mathrm{~h}$

$28 \%$ yield

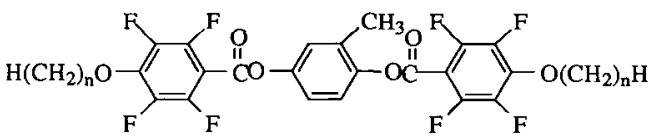

Scheme 8

corresponding sodium $n$-alkoxide, followed by saponification of the $n$-alkoxy ester. The acids are then converted to their acid chlorides using $\mathrm{PCl}_{5}$, and used in situ to diesterify methylhydroquinone to yield the 2,5-bis[(6'-n-alkoxynicotinoyl)oxy]toluenes.

As shown in Scheme 7, the 2,5-bis[(3'-fluoro- $n$-alkoxybenzoyloxy]toluenes are being prepared by first etherifying 4-bromo-2-fluorophenol, and then converting the resulting 4bromo-2-fluoro-( $n$-alkoxy)benzenes to 3 -fluoro-4- $n$-alkoxybenzoic acids by metal-halogen exchange with $n$-BuLi followed by reaction with carbon dioxide. These acids are then coupled with methylhydroquinone using dicyclohexylcarbodiimide (DCC) as the dehydrating agent. Scheme 8 outlines the synthetic route to the 2,5 -bis $\left[\left(2^{\prime}, 3^{\prime}, 5^{\prime}, 6^{\prime}\right.\right.$-tetrafluoro-4' $n$ alkoxybenzoyl)oxy]toluenes. The $n$-alkoxy substituents are introduced by nucleophilic substitution of the para-fluorine on pentafluorobenzoic acid using the corresponding sodium $n$-alkoxides. These 4- $n$-alkoxytetrafluorobenzoic acids will then be coupled with methylhydroquinone using DCC.

Tab. 6. Thermotropic behavior of derivatives of 1,4-bis[(4'-methoxybenzoyl)oxy]toluenes.

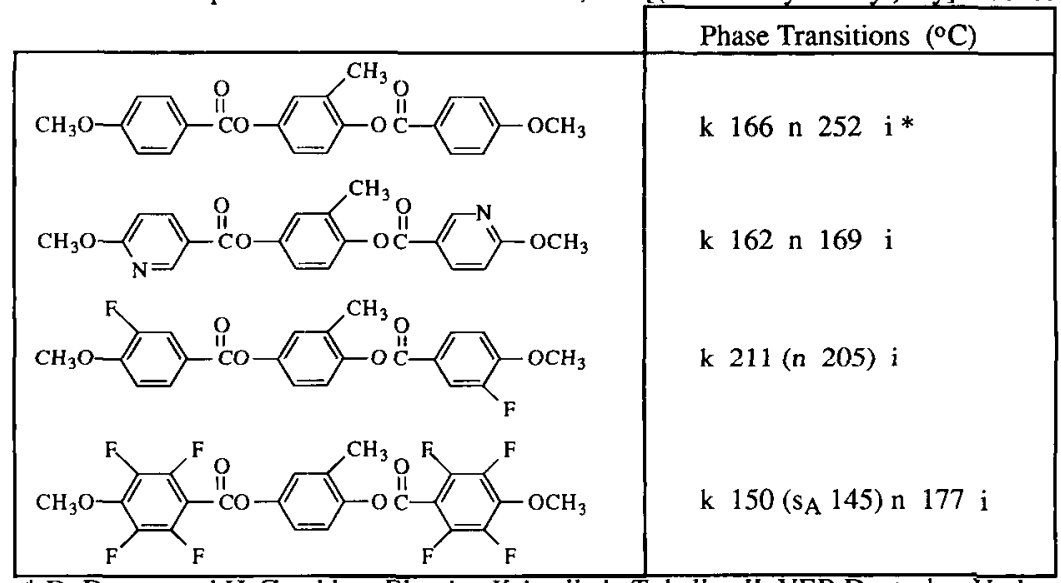

* D. Demus and H. Zaschke, Flussige Kristalle in Tabellen II, VEB Deutscher Verlag: Leipzig, 1984. 
The thermotropic behavior of the model compounds with methoxy substituents are summarized in Tab. 6. Comparison with the thermotropic behavior of 2,5-bis[(4'methoxybenzoyl)oxy]toluene demonstrates that the symmetrical introduction of fluorine substituents suppresses isotropization much more than melting, resulting in a net destabilization of the nematic mesophase. For example, complete fluorination of the terminal aromatic groups suppresses isotropization by $75^{\circ} \mathrm{C}$, whereas melting is suppressed by only 16 ${ }^{\circ} \mathrm{C}$. This reduces the temperature window of the nematic mesophase of 2,5-bis $\left[\left(2^{\prime}, 3^{\prime}, 5^{\prime}, 6^{\prime}-\right.\right.$ tetrafluoro-4'-methoxybenzoyl)oxy]toluene to $59^{\circ} \mathrm{C}$, compared to an $86{ }^{\circ} \mathrm{C}$ nematic temperature window exhibited by 2,5-bis[(4'-methoxybenzoyl)oxy]toluene. In addition, 2,5bis- $\left[\left(2^{\prime}, 3^{\prime}, 5^{\prime}, 6^{\prime}\right.\right.$-tetrafluoro-4'-methoxybenzoyl)oxy]toluene exhibits a monotropic $\mathrm{s}_{\mathrm{A}}$ mesophase which is observed only on cooling. Symmetrical difluorination actually increases the melting point of 2,5-bis[( 3 '-fluoro-4'-methoxybenzoyl)oxy]toluene, such that the nematic mesophase is monotropic. As explained by Gray (Ref. 20), lateral substituents usually exert two opposing effects. While the change in the molecular polarizability may increase the mesophase thermal stability, the decrease in the length/breadth ratio causes a decrease. The latter effect usually dominates. This is true for both lateral methyl (Ref. 21) and fluoro (Ref. 22) substitution in diphenylacetylene derivatives, although the smaller fluorine substituent has less of a destabilizing effect than does methyl.

Symmetrical replacement of the aromatic rings with heteroaromatic rings also destabilizes isotropization more than melting. This is clearly seen with 2,5 -bis [ $6^{\circ}-$ methoxynicotinoyl)oxy]toluene, whose melting point is suppressed $4^{\circ} \mathrm{C}$ relative to that of $2,5-$ bis[( $4^{\prime}$-methoxybenzoyl)oxy]toluene, whereas its nematic-isotropic transition is suppressed by $83^{\circ} \mathrm{C}$, resulting in a nematic temperature window of only $7^{\circ} \mathrm{C}$ instead of $86^{\circ} \mathrm{C}$ as in the parent compound. 3,6-Bis[(4'-methoxybenzoyl)oxy]pyridazine exhibits only a melting endotherm on its first heating scan at $168{ }^{\circ} \mathrm{C}$ which is approximately the same as that of 2,5-bis[(4'methoxybenzoyl)oxyltoluene, demonstrating that the nematic mesophase is monotropic or virtual.

We expect these structural variations to have similar effects on the thermotropic behavior of polynorbornenes laterally attached with the corresponding mesogens. The model compounds can be functionalized and attached to a polymerizable norbornene group as outlined in Scheme 9 using 2,5-bis[(3'-fluoro-4'-methoxybenzoyl)oxy]toluene as an example. The model compounds are brominated at the benzylic position using $\mathrm{Br}_{2}$ under free radical conditions, and then esterified with potassium bicyclo[2.2.1]hept-2-ene-5-carboxylate in the presence of a phase transfer catalyst. The resulting monomers will be polymerized by ringopening metathesis polymerization using $\mathrm{Mo}\left(\mathrm{CHMe}_{2} \mathrm{Ph}\right)\left(\mathrm{N}-2,6-\mathrm{C}_{6} \mathrm{H}_{3}-i-\mathrm{Pr}_{2}\right)(\mathrm{O}-t-\mathrm{Bu})_{2}$ as the initiator. Tab. 7 demonstrates that symmetrical difluorination of the mesogen has the same effect on the laterally attached SCLCP as it does on the model compound. That is, isotropization is destabilized, whereas the glass transition is increased slightly, such that the temperature window of the nematic mesophase appears over only $25^{\circ} \mathrm{C}$ rather than over $66^{\circ} \mathrm{C}$ as in the parent polymer.

Figures 2 and 3 present the UV/Vis spectra of 3,6-bis[(4'-methoxybenzoyl)oxy]- 
pyridazine and 2,5-bis[(6'-methoxynicotinoyl)oxy]toluene, respectively, and their 1:1 mixtures with 2,5-bis[(3'fluoro-4'-methoxybenzoyl)oxy]toluene and 2,5-bis[(2',3',5',6'-tetrafluoro-4'methoxybenzoyl)oxy]toluene in acetonitrile. The lack of any new absorption(s) at longer wavelengths, even if the spectra are magnified, indicate that neither heterocyclic derivative forms an EDA complex with either of the fluorinated derivatives. That is, the spectra of the mixtures are simply a composite of the two components, and all solutions in all combinations are colorless. In addition, neither potential donor exhibits a charge transfer band with tetracyanoethylene (TCNE), which is a strong electron acceptor. The solid-state behavior of $1: 1$ mixtures of 3,6-bis[(4'methoxybenzoyl)oxy]pyridazine and 2,5-bis[(3'-fluoro-4'-methoxybenzoyl)oxy]toluene, and of 3,6-bis[(4'-nbutoxybenzoyl)oxy]pyridazine and 2,5bis[(3'-fluoro-4'- $n$-butoxybenzoyl)oxy]toluene are also simple composites of the two components, with the<smiles>COc1ccc(C(=O)Oc2ccc(OC(=O)c3ccc(OC)c(F)c3)c(C)c2)cc1F</smiles>

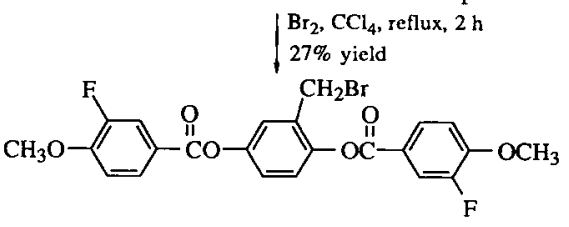

TBAH, THF, DMSO $60^{\circ} \mathrm{C}, 18 \mathrm{~h}, 78 \%$ yield
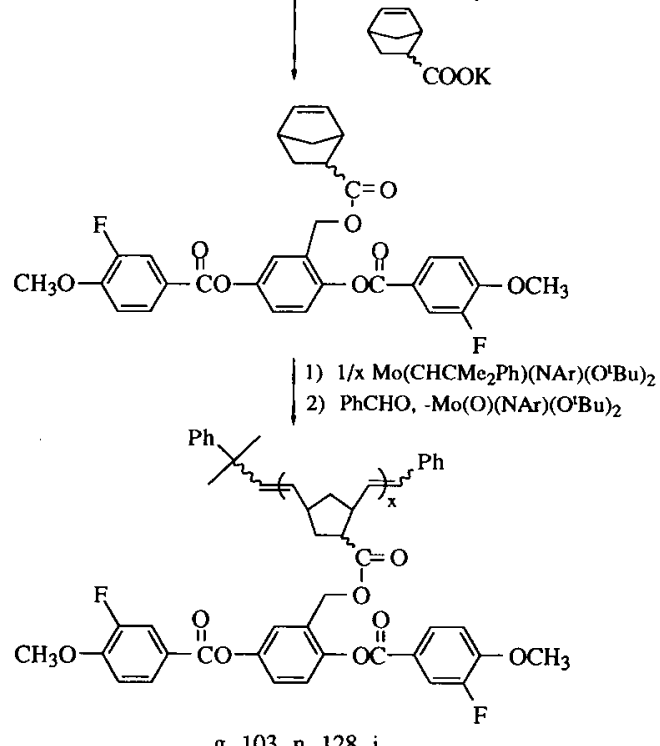

presence of the fluorinated compounds providing no stabilization of the 3,6-

\section{Scheme 9} bis[(4'-n-alkoxybenzoyl)oxy]pyridazines towards rearrangement.

These combinations therefore do not appear to be viable candidates for inducing smectic mesophase formation in SCLCPs with laterally attached mesogens by the formation of EDA interactions. Nevertheless, smectic mesophases have been induced in at least one other system which didn't exhibit a charge transfer band in its UV/Vis spectra (Ref. 23). More promising candidates for potential electron-donors are the aniline derivatives shown in Scheme 5; aniline derivatives such as 4,4'-bis( $n$-alkylamino)biphenyls have been used as electrondonors in studies of low molar mass liquid crystals (Ref. 24). Derivatives resembling more traditional electron acceptors may also be necessary. For example, 2,5-bis[(4'-(2", 2"dicyanoethenyl)benzoyl)oxy]toluene would be similar to the 4-(2',2'-dicyanoethenyl)phenyl-4$n$-alkoxybenzoates used in mixtures with $4,4^{\prime}$-bis ( $n$-alkylamino)biphenvls (Ref. 24 ). 


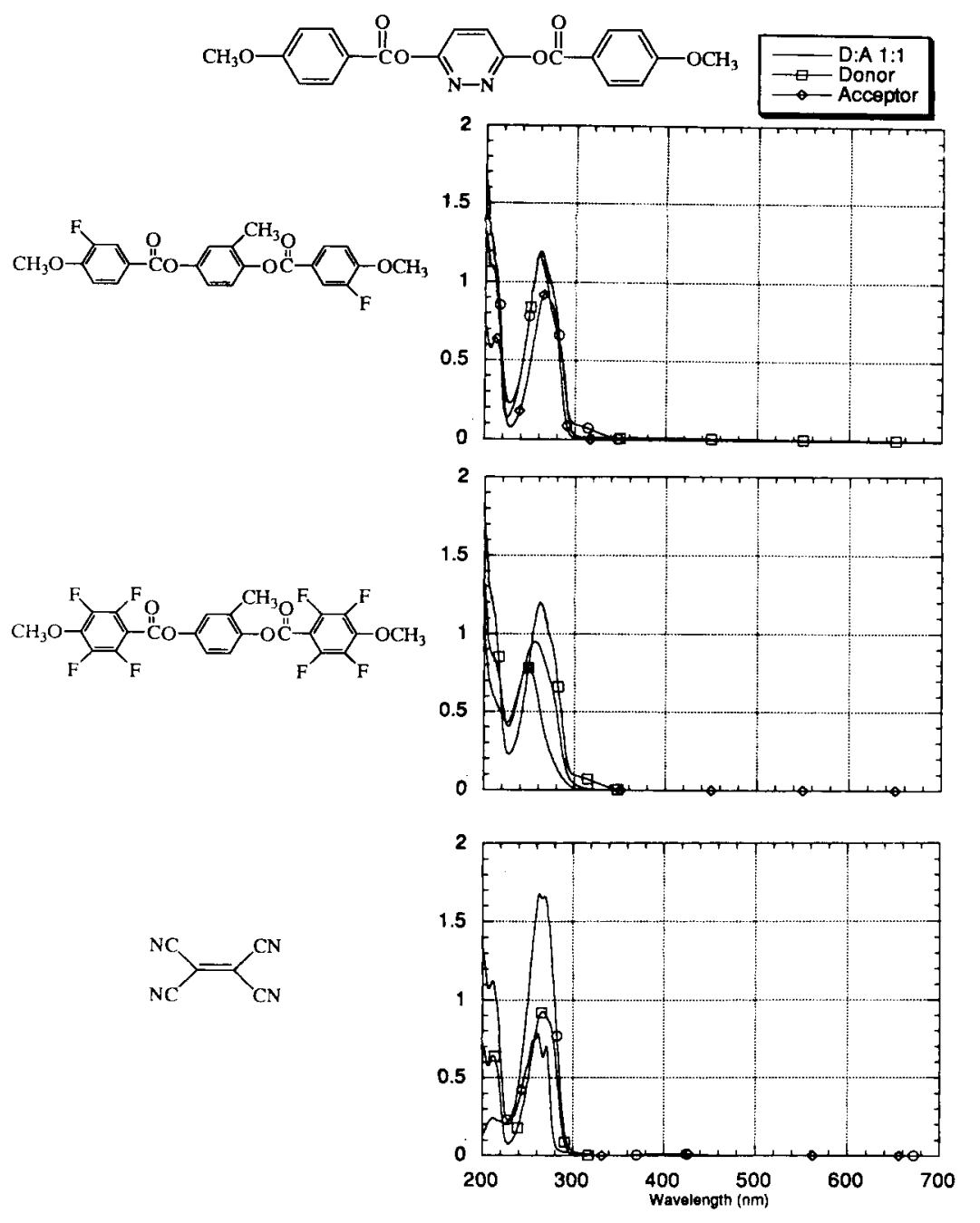

Fig. 2. UV/Vis spectra of 3,6-bis[(4'-methoxybenzoyl)oxy]pyridazine with 2,5-bis[( 3 '-fluoro$4^{\prime}$-methoxybenzoyl)oxy $]$ toluene, 2,5 -bis $\left[\left(2^{\prime}, 3^{\prime}, 5^{\prime}, 6^{\prime}\right.\right.$-tetrafluoro- $4^{\prime}$-methoxybenzoyl)oxy $]$ toluene and tetracyanoethylene in acetonitrile. 

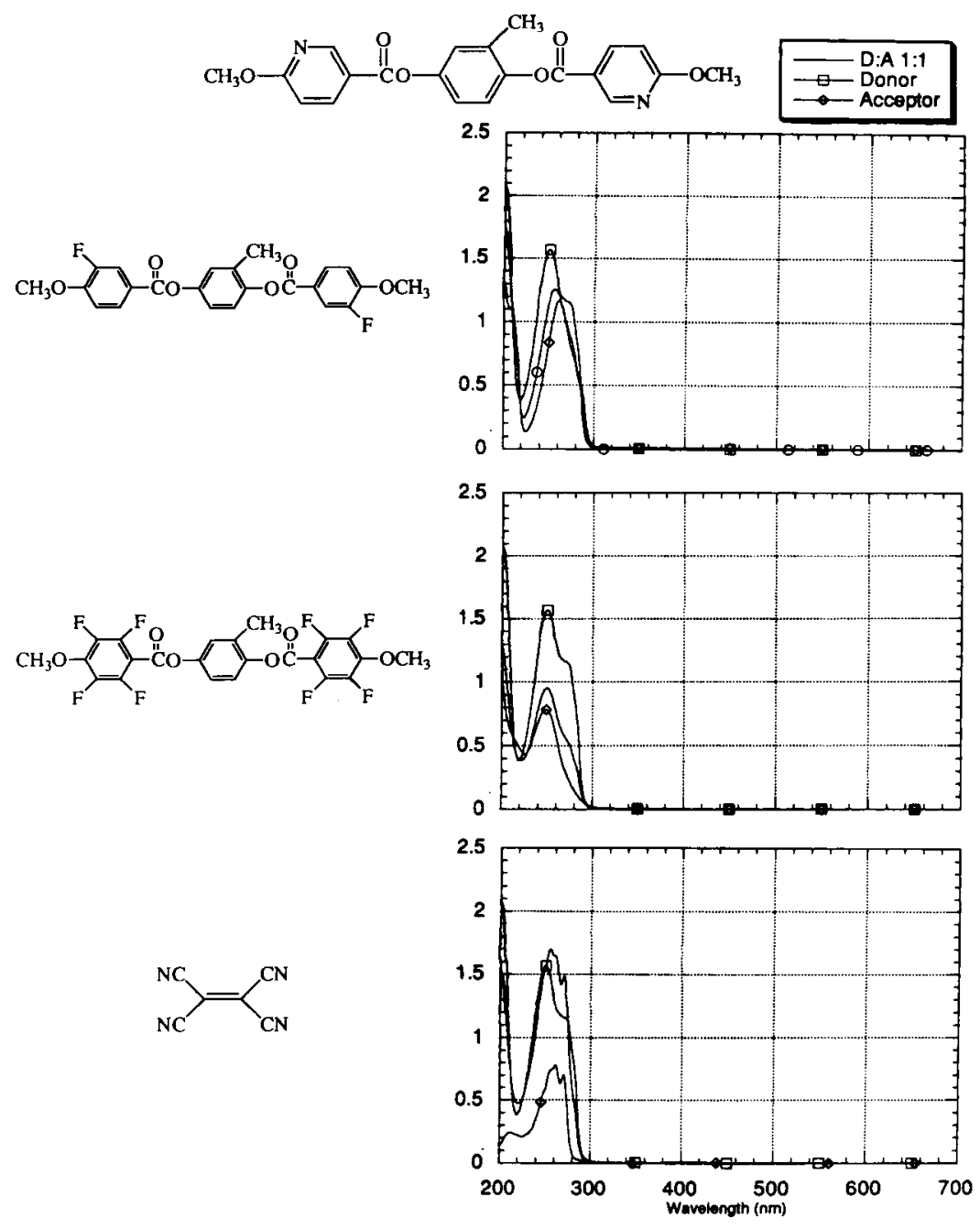

Fig. 3. UV/Vis spectra of 2,5-bis[(6'-methoxynicotinoyl)oxy]toluene with 2,5-bis[(3'-fluoro-4'methoxybenzoyl)oxy]toluene, 2,5-bis[ $\left(2^{\prime}, 3^{\prime}, 5^{\prime}, 6^{\prime}\right.$-tetrafluoro-4'-methoxybenzoyl)oxy]toluene and tetracyanoethylene in acetonitrile. 


\section{ACKNOWLEDGMENTS}

Acknowledgments are made to the donors of The Petroleum Research Fund, administered by the ACS, for financial support, and to the National Science Foundation through an NSF Young Investigator Award (C.P.: 1994-1999).

\section{REFERENCES}

(1) P. LeBarney and J.C. Dubois, "The chiral and smectic $C$ liquid crystal side chain polymers," in Side Chain Liquid Crystal Polymers; C.B. McArdle, Ed., Chapman and Hall, New York, 1989, ch. 5.

(2) J.W. Goodby, J. Mater. Chem., 1, 307 (1991).

(3) D. Demus and H. Zaschke, Flussige Kristalle in Tabellen II; VEB Deutscher Verlag, Leipzig, 1984.

(4) C. Pugh, S.K. Andersson and V. Percec, Liq. Cryst., 10, 229 (1991).

(5) (a) F. Hessel and H. Finkelmann, Polym. Bull., 14, 375 (1985); (b) F. Hessel, R.-P. Herr and H. Finkelmann, Makromol. Chem., 188, 1597 (1987); (c) Q.-F. Zhou, H.M. Li and X.-D. Feng, Macromolecules, 20, 233 (1987); (d) Q.-F. Zhou, H.-M. Li and X.-D. Feng, Mol. Cryst. Liq. Cryst., 155, 73 (1988); (e) F. Hessel and H. Finkelmann, Makromol. Chem., 189, 2275 (1988); (f) P. Keller, F. Hardouin, M. Mauzac and M.F. Achard, Mol. Cryst. Liq. Cryst., 155, 171 (1988); (g) F. Hardouin, S. Mery, M.F. Achard, M. Mauzac, P. Davidson and P. Keller, Liq. Cryst., 8, 565 (1990); (h) R.W. Lewthwaite, G.W. Gray and K.J. Toyne, J. Mater. Chem., 2, 119 (1992); (i) V. Percec and D. Tomazos, J. Mater. Chem., 3, 643 (1993).

(6) C. Pugh and R.R. Schrock, Macromolecules, 25, 6593 (1992).

(7) (a) W. Mahler, D. Guillon and A. Skoulios, Mol. Cryst. Liq. Cryst., Lett., 2, 111 (1985); (b) T.P. Russell, J.F. Rabolt, R.J. Twieg, R.L. Siemens and B.L. Farmer, Macromolecules, 19, 1135 (1986); (c) J. Hoepken, C. Pugh, W. Richtering and M. Moeller, Makromol. Chem., 189, 911 (1988); (d) J. Hoepken and M. Moeller, Macromolecules, 25, 2482 (1992).

(8) See for example: (a) S. Takahashi, Y. Kuroyama, K. Sonogashira and N. Hagihara, Synthesis, 627 (1980); (b) S.J. Havens and P.M. Hergenrother, J. Org. Chem., 50, 1763 (1985); (c) J. Zhang and J.S. Moore, J. Am. Chem. Soc., 116, 2655 (1994).

(9) W. Tao, S. Nesbitt, and R.F. Heck, J. Org. Chem., 55, 63 (1990).

(10) C.E. Castro, E.J. Gaughan and D.C. Owsley, J. Org. Chem., 31, 4071 (1966); and references therein.

(11) R.L. Letsinger, E.N. Oftedahl and J.R. Nazy, J. Am. Chem. Soc., 87, 742 (1965).

(12) O. Kazumi, M. Furuune, M. Enna, M. Miura and M. Nomura, J. Org. Chem., 58, 4716 (1993).

(13) S. Kajigaeshi, T. Kakinami, H. Yamasaki, S. Fujisaki, M. Kondo and T. Okamoto, Chem. Lett.Jpn., 2109 (1987). 
(14) J. S. Moore, E.J. Weinstein and Z. Wu, Tetrahedron Lett., 32, 2465 (1991).

(15) (a) H.C. Brown and S. Krishnamurthy, J. Am. Chem. Soc., 95, 1669 (1973); (b) H.C. Brown, S.C. Kim and S. Krishnamurthy, J. Org. Chem., 45, 1 (1980).

(16) T. Doi, Y. Sakurai, A. Tamatani, S. Takenaka, S. Kusabayashi, Y. Nishihata and H. Terauchi, J. Mater. Chem., 1, 169 (1991); and references therein.

(17) F. H. Herbstein in Perspectives in Structural Chemistry, vol IV, eds. J. D. Dunitz and J. A. Ibers, Wiley, New York, 1971, p 166.

(18) K. Eichenberger, A. Staehlin and J. Druey, Helv. Chim. Acta, 37, 837 (1954).

(19) (a) D. Stefanye and W.L. Howard, J. Org. Chem., 19, 115 (1954); (b) H. Feuer and H. Rubinstein, J. Am. Chem. Soc., 80, 5873 (1958).

(20) G.W. Gray, C. Hogg and D. Lacey, Mol. Cryst. Liq. Cryst., 67, 1 (1981).

(21) (a) C. Pugh and V. Percec, Polym. Bull., 23, 177 (1990); (b) C. Pugh and V. Percec, Mol. Cryst. Liq. Cryst., 178, 193 (1990).

(22) (a) C. Pugh and V. Percec, Chem. Mater., 3, 107 (1991); (b) C. Pugh, S.K. Andersson and V. Percec, Liq. Cryst., 10, 229 (1991).

(23) C. T. Imrie, F. E. Karasz and G. S. Attard, Liq. Cryst., 9, 47 (1991).

(24) D. Demus, G. Pelzl, N. K. Sharma and W. Weissflog, Mol. Cryst. Liq. Cryst., 76, 241 (1981). 